\title{
Late-stage disease at presentation to an HIV clinic in eastern Tanzania: A retrospective cross-sectional study
}

\section{H Mhozya ${ }^{1}$, D Bintabara ${ }^{3}$, S Kibusi ${ }^{3}$, E Neilson ${ }^{2,4}$, BC Mpondo ${ }^{2 *}$}

1.Buguruni Health Centre, Ilala Municipal, Dar es Salaam, Tanzania

2. School of Medicine, College of Health Sciences, University of Dodoma, Dodoma, Tanzania

3.School of Nursing and Public health, College of Health Sciences, University of Dodoma, Dodoma, Tanzania

4.Peace Corps/SEED Global Health Service Partnership, Massachusetts General Hospital Center for Global Health, Boston, Massachusetts, USA

Bonaventura C.T Mpondo, Department of Internal Medicine, School of Medicine, College of Health Sciences, The University of Dodoma e-mail: boniempondo@gmail.com

\section{Abstract}

\section{Background}

Late presentation and delayed treatment initiation is associated with poor outcomes in patients with HIV. Little is known about the stage at which HIV patients present at HIV clinics in Tanzania.

\section{Aim:}

This study aimed at determining the proportion of HIV patients presenting with WHO clinical stages 3 and 4 disease, and the level of immunity at the time of enrollment at the care and treatment center.

\section{Methods}

A retrospective cross-sectional study was conducted among $366 \mathrm{HIV}$ infected adults attending HIV clinic at Mwananyamala Hospital in Dar es Salaam, Tanzania. Data were obtained from the care and treatment clinic database.

\section{Results}

Late stage disease at the time of presentation was found in $276(75.4 \%)$ of the patients; out of whom $153(41.8 \%)$ presented with CD4 count $<200$ cells/ul and $229(62.6 \%)$ presented with WHO clinical stage 3 or 4 at the time of clinic enrollment. Strategies to improve early diagnosis and treatment initiation should be improved.

\section{Introduction}

Existing evidence shows that treatment outcomes in HIV patients are related to patient health status at the time of ART initiation. Good treatment outcomes have been associated with early initiation of treatment. Delayed initiation of ART has been associated with increased morbidity and mortality ${ }^{1}$ impaired immune recovery ${ }^{2}$ increased financial strain on the health care system, ${ }^{3}$ and an increased risk of transmission of the disease ${ }^{4}$.

Several reports from developed countries have shown that a relatively large percent of people with HIV present late for HIV care and treatment ${ }^{5}$. There is limited published data on HIV stage at presentation among sub-Saharan African patients. Little is known about the proportion and characteristics of patients presenting to HIV care and treatment clinics in the later stages of the disease. Most reports in sub-Saharan Africa focus on the CD4 count at ART initiation and reveal that a majority of patients initiate ART at low CD4 levels ${ }^{6}$. This study aimed at determining the proportion of HIV patients presenting with WHO clinical stages 3 and 4 disease, and the level of immunity at the time of enrollment at the HIV care and treatment center at Mwananyamala Hospital in Dar es Salaam, Tanzania.

\section{Methods}

\section{Study design, setting, and participants}

A clinic-based retrospective cross-sectional study was conducted among HIV-infected adults attending the care and treatment clinic at Mwananyamala Hospital, between January and December 2013. Mwananyamala Hospital is a regional referral hospital, located in Kinondoni District, Dar es Salaam, Tanzania. It caters to a population of approximately 1.5 million people. The HIV care and treatment clinic has a total of 28,000 clients, of whom 10,500 are on ART.

\section{Sample size and sampling procedure}

The sample size was obtained using the formula for single population proportion. In order to get a representative sample, a systematic sampling procedure was used to select the study participants from the sampling list, which contained a total of 9164 patients attending HIV clinic in the year 2013. This total number of patients was divided by the sample size required in order to calculate the sampling intervals $(\mathrm{k}=25)$. If a selected participant had missing data, the next patient was selected instead.

\section{Data collection}

A specially designed data collection tool was used for recording the demographic data, clinical characteristics, and all laboratory results. Data were obtained from the care and treatment clinic database.

\section{Measurements}

\section{Outcome variables}

WHO clinical stage and the CD4 cell count at the time of enrollment were used as the outcome variable for this analysis. The WHO clinical stages were categorized for each patient dichotomously as severe (stage 3 and 4) or not severe (stage 1 and 2). CD4 cell count recordings were also dichotomized, as either $<200$ cells $/ \mathrm{mm} 3$ or $\geq 200$ cells $/ \mathrm{mm} 3$. The timing of patient presentation was considered late or early: those patients presenting with either HIV WHO clinical stage 3 or 4 or $\mathrm{CD} 4<200$ cells $/ \mathrm{mm} 3$ were defined as late presenters.

\section{Independent variables}

Independent variables included the sociodemographic information recorded in the database, including the age, gender, and marital status.

\section{Statistical analysis}

Continuous variables were summarized by medians and interquartile ranges (IQRs), and categorical variables were summarized by frequencies and percentages. Data were analyzed using Stata/IC version 10.1 (College Station, Texas, USA). The presentation was dichotomized, so that those with WHO clinical stage 3 or 4 disease or a CD 4 count $<200$ cells $/ \mathrm{mm} 3$ were considered late presenters for the analysis, and those with stage 1 or 2 disease or a CD 4 count $\geq 200$ cells $/ \mathrm{mm} 3$ were considered early presenters.

\section{Ethical considerations}

The study was approved by the Institutional Ethics Review Board of the University of Dodoma. Permission to conduct the study was also granted by the district medical officer and 
the medical officer in charge of Mwananyamala Hospital.

\section{Results}

\section{Study population and patient characteristics}

A total of 366 patients participated in this study. Out of these, 235 (64.2\%) were females and 131 (35.8\%) were males. The median age of the study participants was 36 years (IQR 30-43) and the median CD4 count at the time of enrolment to the clinic was 202.5 cells $/ \mathrm{mm} 3$ (IQR 104-300). Out of the 366 study participants, 160 (43.7\%) were married, 130 $(35.5 \%)$ were single, $32(8.7 \%)$ were widows or widowers, 26 (7.1\%) were divorced, and 18 (4.9\%) were cohabiting (Table 1).

\section{Stage of disease and level of immunity at clinic enrolment}

At the time of enrolment to the clinic, 276 patients $(75.4 \%)$ had late-stage disease. Out of these, 196 patients $(53.6 \%)$ met WHO clinical stage 3 criteria and 33 patients $(9.0 \%)$ had WHO clinical stage 4 disease. In terms of the level of immunity, 153 patients $(41.8 \%)$ were enroled with a CD 4 cell count $<200$ cells $/ \mathrm{mm} 3,76$ patients $(20.8 \%)$ with a CD 4 count between 200 and 350 cells $/ \mathrm{mm} 3$, and 75 patients $(20.5 \%)$ with a CD4 count between 351 and 500 cells $/ \mathrm{mm} 3$. Only 62 patients $(16.9 \%)$ were enroled at the clinic with a CD4 count of $\geq 500$ cells $/ \mathrm{mm} 3$ (Table 1 ).

\section{Discussion}

In this study, the majority of participants were late presenters. The proportion of those presenting at clinical stage 3 or 4 is slightly higher than a study done in Uganda, which found that $40 \%$ of the patients were enroled with a WHO clinical stage 3 or 4 designation ${ }^{6}$. Several other studies have also shown that the majority of patients in sub-Saharan Africa are diagnosed and enroled in care and treatment services with low CD4 counts?

Reports of the trends regarding late presentation in subSaharan Africa show that efforts focused on increasing HIV testing coverage have had positive effects, as the proportion of late presentation has been decreasing. Low risk of late presentation was associated with enrolment through prevention of mother-to-child transmission (PMTCT) protocols and residing in a region with wide coverage of HIV testing ${ }^{5}$. Emphasis on male involvement in PMTCT can also increase early testing for HIV.

Late presentation has been shown to impose a number of challenges in the management of HIV patients. It is often associated with mortality, either before or after ART initiation'. Very low CD4 counts at the time of ART initiation $(<200$ cells $/ \mathrm{mm} 3)$ has been associated with increased risk of acquiring one or more opportunistic infections; this increases the risk of developing immune reconstitution inflammatory syndrome after ART initiation ${ }^{10}$. It also increases the risk of incomplete immune recovery.

Table 1: Baseline sociodemographic and clinical characteristics of HIV-infected patients attending Mwananyamala Care and Treatment Clinic, January to December 2013 ( $n=366)$

\begin{tabular}{|c|c|}
\hline Age $\mathrm{Characteristic}^{\text {Che }}$ & Number (\%) or Median (IQR) \\
\hline & $36(30-43)$ \\
\hline $\operatorname{sex}$ & $235(64.2)$ \\
\hline Male & $131(35.8)$ \\
\hline $\begin{array}{c}\text { Female } \\
\text { Marital status }\end{array}$ & \\
\hline Single & $160(122)$ \\
\hline Married & $18(49)$ \\
\hline Cohabiting & $32(8.7)$ \\
\hline Widowed & $26(7.1)$ \\
\hline $\begin{array}{l}\text { Divorced } \\
\text { CP4 count at enrollment (cells/ul) } \\
\text { WHO clinical stage }\end{array}$ & $\begin{array}{c}202.5(104-300) \\
47(12.8 \%)\end{array}$ \\
\hline Stage 1 & $90(24.6 \%)$ \\
\hline Stage 2 & $196(53.6 \%)$ \\
\hline Stage 3 & 33 (9.0\%) \\
\hline $\begin{array}{l}\text { Stage } 4 \\
\text { CD4 cell count (cells/ul) }\end{array}$ & 153 (41.8\%) \\
\hline$<200$ & $76(20.8 \%)$ \\
\hline $200-350$ & 75 (20.5\%) \\
\hline $351-500$ & 62 (16.9\%) \\
\hline WHO clinical stage 3 or 4 (late stage disease) & $229(62.6 \%)$ \\
\hline Yes & $137(37.4 \%)$ \\
\hline
\end{tabular}


In our study, the median CD4 count at the time of ART initiation was 202.5 cells $/ \mathrm{mm} 3 ; 153$ of our study subjects $(41.8 \%)$ started ART with CD4 < 200 cells/ul. This study had several limitations. It was a cross-sectional study and is prone to selection bias. This was a sample of clinic attendees only. The analyzed late presentation may not truly represent patients who have never attended the clinic. The data used for this analysis comes from the records of routine clinic encounters, which lack some important variables that could have been used to assess other possible predictors of late presentation. In addition, the analysis was based on a single clinic; therefore, results may not be generalizable. The high percentage of late-stage disease and late presenters found in this study suggests possible barriers to HIV care in Tanzania. Late presentation reduces the benefits of ART, increases the chances of continuing HIV transmission, and increases the costs of medical care. This study highlights the need to develop and implement strategies that will facilitate early diagnosis and entry into HIV care.

\section{Conclusion}

Despite ongoing efforts to increase HIV testing coverage in Tanzania, late-stage disease at the time of enrolment is still high. The majority of patients are still enroled with WHO clinical stage 3 or 4 disease or with a CD 4 count $<200$ cells/ $\mathrm{mm} 3$. There is a need to develop and implement strategies that will further increase HIV testing coverage and improve the number of patients who are diagnosed and enroled in HIV care early, in order to ensure better treatment outcomes.

\section{Acknowledgments}

We thank the management and all the staff of Mwananyamala HIV Care and Treatment Clinic for their support. We thank all patients who agreed to participate in the study.

\section{References}

1. Wajanga B, Webster LE, Peck RN, Downs JA, Mate K, Smart LR, et al. Inpatient mortality of HIV-infected adults in sub-Saharan Africa and possible interventions: a mixed methods review. BMC Health Serv Res [Internet]. 2014 Dec 3 [cited 2015 Feb 21];14(1):627. Available from: http://www. pubmedcentral.nih.gov/articlerender.fcgi?artid $=4265398 \& \mathrm{t}$ ool $=$ pmcentrez\&rendertype $=$ abstract .

2. Kelley CF, Kitchen CMR, Hunt PW, Rodriguez B, Hecht FM, Kitahata M, et al. Incomplete peripheral CD4+ cell count restoration in HIV-infected patients receiving longterm antiretroviral treatment. Clin Infect Dis [Internet]. 2009 Mar 15 [cited 2015 Feb 21];48(6):787-94. Available from: http://www.pubmedcentral.nih.gov/articlerender.fcgi?artid $=2720023 \&$ tool $=$ pmcentrez\&rendertype $=$ abstract.

3. Krentz HB, Auld MC, Gill MJ. The high cost of medical care for patients who present late (CD4 $<200$ cells/microL) with HIV infection. HIV Med [Internet]. 2004 Mar [cited 2015 Feb 19];5(2):93-8. Available from: http://www.ncbi. nlm.nih.gov/pubmed/15012648.
4. Lima VD, Johnston K, Hogg RS, Levy AR, Harrigan PR, Anema A, et al. Expanded access to highly active antiretroviral therapy: a potentially powerful strategy to curb the growth of the HIV epidemic. J Infect Dis [Internet]. 2008 Jul 1 [cited 2015 Feb 19];198(1):59-67. Available from: http://www.ncbi.nlm.nih.gov/pubmed/18498241.

5. Hoffman S, Wu Y, Lahuerta M, Kulkarni SG, NuwagabaBiribonwoha H, Sadr W El, et al. Advanced disease at enrollment in HIV care in four sub-Saharan African countries: change from 2006 to 2011 and multilevel predictors in 2011. AIDS [Internet]. 2014 Oct 23 [cited 2015 Feb 18];28(16):2429-38. Available from: http://www.ncbi. nlm.nih.gov/pubmed/25136842.

6. Kigozi IM, Dobkin LM, Martin JN, Elvin H, Muyindike W, Mmed M, et al. Late disease stage at presentation to an HIV clinic in the era of free antiretroviral therapy in sub-Saharan Africa Isaac. J Acquir Immune Defic Syndr. 2010;52(2):1-21.

7. Braitstein P, Brinkhof MWG, Dabis F, Schechter M, Boulle A, Miotti P, et al. Mortality of HIV-1-infected patients in the first year of antiretroviral therapy: comparison between low-income and high-income countries. Lancet [Internet]. 2006 Mar 11 [cited 2015 Jan 30];367(9513):817-24. Available from: http://www.ncbi.nlm.nih.gov/pubmed/16530575.

8. Byamugisha R, Tylleskär T, Kagawa MN, Onyango S, Karamagi CA, Tumwine JK. Dramatic and sustained increase in HIV-testing rates among antenatal attendees in Eastern Uganda after a policy change from voluntary counselling and testing to routine counselling and testing for HIV: a retrospective analysis of hospital records, 2002-20. BMC Health Serv Res [Internet]. 2010 Jan [cited 2015 Feb 22];10:290. Available from: http://www.pubmedcentral.nih. gov $/$ articlerender.fcgi? artid $=2964695 \&$ tool $=$ pmcentrez\&re ndertype $=$ abstract.

9. Girardi E, Sabin CA, Monforte AD. Late diagnosis of HIV infection: epidemiological features, consequences and strategies to encourage earlier testing. J Acquir Immune Defic Syndr [Internet]. 2007 Sep [cited 2015 Feb 21];46 Suppl 1:S3-8. Available from: http://www.ncbi.nlm.nih. gov/pubmed/17713423.

10. Huruy K, Mulu A, Mengistu G, Shewa-Amare A, Akalu $A$, Kassu A, et al. Immune reconstitution inflammatory syndrome among HIV/AIDS patients during highly active antiretroviral therapy in Addis Ababa, Ethiopia. Jpn J Infect Dis [Internet]. 2008 May [cited 2015 Feb 21];61(3):205-9. Available from: http://www.ncbi.nlm.nih. gov/pubmed/18503170. 